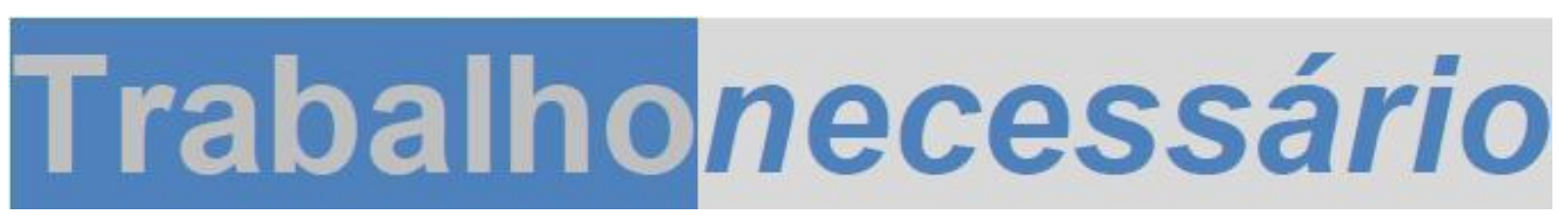

Issn: 1808 - 799X

ano 12, no $18-2014$

\title{
EDWARD P. THOMPSON: MÉTODO, CATEGORIAS ANALÍTICAS E FENÔMENOS EDUCACIONAIS ${ }^{1}$
}

\author{
Zuleide S. Silveira ${ }^{2}$
}

\section{Resumo}

Este texto tem como objetivo primeiro resgatar as contribuições teóricometodológicas do historiador inglês Edward Palmer Thompson (1924-1993), tendo em conta seu debate sobre a "lógica histórica" e as categorias analíticas da concepção materialista da história. Segundo, recuperar, nos limites deste artigo, a discussão em torno do conceito de cultura e de alguns de seus aspectos junto às noções de classe social, luta de classes, consciência e experiência de classe, analisando criticamente as implicações do pensamento pós-moderno nos estudos culturais. Em seguida, busca argumentar a pertinência do contributo thompsoniano para a investigação dos fenômenos educacionais retomando as categorias classe social, consciência de classe, cultura e experiência. À guisa de conclusão, retoma o método teórico-metodológico de Thompson para afirmar sua atualidade e contribuição à análise dos fenômenos educacionais.

Palavras-chave: Edward P. Thompson; Materialismo histórico dialético; Categorias analíticas.

\footnotetext{
${ }^{1}$ A produção deste texto parte de minha mediação na Mesa Educação e emancipação: a História como processo, integrante do Seminário Trabalho, História e Experiência de Classe: Thompson 50 anos depois, promovido pelo Neddate, realizado na Faculdade de Educação, Campus Gragoatá, no dia 23/09/2013.

2 Professora do Programa de Pós-Graduação em Educação da Universidade Federal Fluminense (UFF); Professora Adjunta da Faculdade de Educação da mesma Universidade; Membro Permanente do Neddate.
}

TrabalhoNecessário - www.uff.br/trabalhonecessario; Ano 12, № 18/2014. 


\section{Trabalhonecessário}

Issn: $1808-799 X$

ano 12, no $18-2014$

\section{Abstract}

This text has the main objective to rescue the theoretical and methodological contributions of the English historian Edward Palmer Thompson (1924-1993), taking into account its debate on the "historical logic" and the analytical categories of materialist conception of history. Second, within the limits of this article, it aims to retrieve the discussion around the concept of culture and some of its aspects seen in conjunction with the notions of social class, struggle of class, class consciousness and experience, so as to analyzing in a critical manner the implications of postmodern thought in cultural studies. Continuously, it recovers the categories of social class, class consciousness, culture and experience to argue the relevance of thompsonian contribution to the research of education phenomena. In conclusion, retakes the theoretical-methodological of Thompson to assert its relevance and contribution to the analysis of educational phenomena.

Key-words: Edward P. Thompson; Dialectical historical materialism; Analytical categories.

\section{Introdução:}

Escrever sobre Edward Thompson (1924 -1993) é voltar-se para o método de investigação sobre as relações sociais de produção e de reprodução da vida ampliada; estabelecer a unidade teoria e ação e tratar de categorias de análise (recheadas de conteúdo histórico e social), que oferecem sugestões para se pensar a realidade brasileira, em geral, e investigar os fenômenos educacionais, em particular. No entanto, se a contribuição de Thompson é relevante, a dificuldade se impõe porquanto não se pode ser absolutamente inovador(a) em relação àquilo o qual tantos têm refletido, analisado, debatido, escrito $\mathrm{e}$ publicado $^{3}$.

A obra de Thompson não versou apenas sobre o movimento operário, mas também sobre os modos de dominação, as classes sociais, a luta de classes e a

\footnotetext{
${ }^{3}$ Refiro-me, entre outros, a Eric Hobsbawm, Ellen Wood, Christopher Hill, Marcelo Badaró Mattos, Antonio Luigi Negro, Alexandre Fortes.
}

TrabalhoNecessário - www.uff.br/trabalhonecessario; Ano 12, № 18/2014. 


\section{Trabalhonecessário}

Issn: 1808 - 799X ano 12,

no $18-2014$

consciência de classe, cultura e experiência de classe, folclore, costumes, crime, protestos (individuais e coletivos). Nesta profícua produção, Thompson toma a história como método, como processo e como política, um modo diverso de se pensar, pesquisar, analisar e redigir a história vista a partir "dos de baixo".

Thompson enfrenta os métodos estrutural-funcionalista, marxista-estruturalista, marxista-existencialista, a ortodoxia fabiana ${ }^{4}$, bem como os equívocos que consistem em separar a dimensão cultural da dimensão social e estas dos fenômenos econômicos. Junto a Raymond Williams e Richard Hoggat, Edward Thompson integra os primeiros intelectuais dos Estudos Culturais ${ }^{5}$ posicionando-se contra o marxismo de Moscou, de cuja ortodoxia stalinista se manifestava no Partido Comunista da Grã-Bretanha (PCGB).

Militante do PCGB até o ano de $1956^{6}$, a Thompson, entre outros historiadores como Eric Hobsbawm, Richard Hoggat, Arthur Morton, Maurice Dobb, Christopher Hill, é imputada a ligação indissolúvel entre militância e produção intelectual. Aliás, há que se destacar a contribuição deste grupo de intelectuais no que diz respeito à organização, no interior do partido, de seções de estudo, que veio substituir as ciências naturais pela história como paradigma de análise marxista, ao mesmo tempo em que, resgatava e aprofundava os estudos de Marx, Engels e Lênin.

Esta mudança possibilitou (i) a crítica à visão etapista da história e seu determinismo econômico-tecnológico; (ii) o questionamento às teses de

\footnotetext{
${ }^{4}$ Refere-se à Fabian Society, fundada em 1883 com o objetivo de "reconstruir a sociedade de acordo com o mais alto ideal moral", recusando vários conceitos marxistas.

${ }^{5}$ Segundo Mulhern (1999), a definição clássica do que veio a ser denominado Estudos Culturais coube a Raymond Williams, de cuja proposta era investigar a criação de significados (descrições, explicações, interpretações, avaliações de todo tipo) na e como parte formativa de um estilo de vida, contestando, assim, o sistema de valores que vinha respaldando o entendimento de crítica cultural capitaneado pelo espanhol José Ortega y Gasset e pelo alemão Thomas Mann.

${ }^{6}$ O Movimento Comunista Internacional entra em crise a partir da denúncia de Nikita Kruschev, então secretário geral do Partido Comunista da União Soviética (PCUS), realizada no XX Congresso do PCUS, em fevereiro de 1956, sobre o período de poder de Joseph Stalin na União Soviética.
}

TrabalhoNecessário - www.uff.br/trabalhonecessario; Ano 12, №18/2014. 


\section{Trabalhonecessário}

Issn: 1808 - 799X

ano 12, no $18-2014$

aburguesamento da classe operária; (iii) a redefinição do campo de debates em torno do desenvolvimento do capitalismo inglês e da Revolução Inglesa do século XVII (Revolução Puritana de 1640 e Revolução Gloriosa de 1688).

Já dissidentes do PCGB, o grupo passa a constituir o principal núcleo do movimento político de esquerda, conhecido como a New $\mathrm{Left}^{7}$, do que Raymond Williams também faz parte. Thompson funda a New Reason ${ }^{8}$, que veio a dar origem, no ano de 1959, à New Left Review ${ }^{9}$. Principal instrumento de debate político e teórico da New Left, a Revista se abre, até os dias que correm, como espaço de debates e divulgação de reflexões da dissidência comunista, que incorporava as contribuições do marxista italiano Antonio Gramsci, bem como de crítica ao stalinismo, à política social-democrata, ao colonialismo e ao armamento nuclear.

Entretanto, este é um contexto de Guerra-Fria e adverso às ideias democrático-socialistas, em que as concepções dos economistas Friedrich Hayek e Milton Friedman se desenvolviam e se fortaleciam em torno daquilo que viria a ser o neoliberalismo com sua afirmação da superioridade do capitalismo como modelo de desenvolvimento insuperável.

Ao mesmo tempo, as críticas em torno da universidade como um modelo de instituição envelhecido, retrógrado e desinteressante ${ }^{10}$, de cuja produção e organização tinham na cultura elemento aglutinador da formação da identidade cultural dos indivíduos e de construção de uma nacionalidade, abrem espaço para

\footnotetext{
7 Nova Esquerda.

${ }^{8}$ Nova Razão

${ }^{9}$ Revista Nova Esquerda

${ }^{10}$ Tanto na Europa, quanto na América Latina desencadeia-se uma série de debates, quer no seio do Estado, quer no espaço universitário, sobre a suposta "crise da universidade" como responsável pelos atrasos do setor produtivo e do desenvolvimento econômico do país, recomendando-se a adoção do modelo norte-americano de universidade em contraposição aos modelos humboldtiano e napoleônico. Neste sentido, a noção de Estado-Nação e o conceito de cultura, nos quais os questionados modelos se apoiavam, passam a perder sua antiga relevância. Para maiores detalhes, ver Silveira (2011).
} 


\section{Trabalhonecessário}

Issn: 1808 - 799X

ano 12, no $18-2014$

a ideia de cultura como esfera dissociada da história, da economia e da política, trazendo nova consideração ao debate cultural.

Raymond Williams, Richard Hoggart e Edward Thompson marcam posição neste debate, incorporando a ideia de uma cultura em comum sob a perspectiva da classe trabalhadora ${ }^{11}$. Entrementes, o grupo que havia dado origem à New Left Review encontrava-se politicamente desarticulado, com dificuldades financeiras e, por fim, dissolve-se.

No ano de 1963, Perry Anderson torna-se o novo editor da Revista e, com ele, um novo grupo conhecido como a segunda nova esquerda promove uma inflexão no debate político, abrindo espaço para autores como Louis Althusser, Ernest Mandel, Balibar, Colletti, entre outros. No ano seguinte, com a vitória do Partido Trabalhista, Perry Anderson e um novo colaborador da Revista, Tom Nairn, aproximam-se do movimento sindical e põem-se a escrever uma série de artigos com ênfase nas questões econômicas em detrimento da luta da classe trabalhadora e da cultura popular (WOOD, 1995). "Claramente, o modelo Anderson-Nairn se aproxima de forma mais estreita da experiência francesa, ou de uma interpretação particular dessa experiência [em especial, o marxismo althusseriano], e nisto eles seguem a tradição marxista predominantemente pré1917" (THOMPSON, 2007, p. 79. Itálico do autor).

Define-se, então, grosso modo, os termos do debate teórico-metodológico que viria polarizar a esquerda inglesa por quase dez anos: de um lado, a ênfase nas experiências sociais, culturais e políticas da formação da classe trabalhadora inglesa; de outro, a incapacidade de a classe trabalhadora tornar-se hegemônica e o seu aburguesamento.

\footnotetext{
${ }^{11}$ Culture and society, 1870-1850 [1958], de Raymond Williams; The use of literacy [1957], de Richard Hoggart; The making of the english working class [1963], de Edward Thompson, foram a trilogia de clássicos sobre a cultura na tradição britânica. Cf. Cevasco, 2008.
} 


\section{Trabalhonecessário}

Issn: 1808 - 799X

ano 12, no $18-2014$

A partir destas considerações, no sentido de cumprir os desafios deste trabalho, recorro aos principais escritos de Thompsom, quais sejam, A formação da classe operária inglesa, A miséria da teoria ou um planetário de erros e As peculiaridades dos ingleses ( e outros escritos), bem às contribuições de Mattos (2012) e Wood (1995; 1999).

\section{Thompson e o materialismo histórico (Dialético)}

Thompson conviveu ativamente com seu tempo, particularmente no que diz respeito à qualidade de vida, aos sofrimentos e às satisfações daqueles que vivem e morrem em época não remida. Tentou resgatar a história dos homens simples, excluídos dos ares de condescendências soprados por conservadores. Criticou o marxismo daqueles que pretendiam ser "mais marxistas do que Marx", recusou o empirismo, o "teorismo ahistórico" e apolítico, o idealismo subjetivista, bem como o determinismo econômico e tecnológico.

A análise de $A$ formação da classe operária inglesa, $A$ miséria da teoria, As peculiaridades dos ingleses, entre outros escritos, bem como o movimento de investigação empreendido por Thompson sublinham o duplo trabalho crítico, tal como Marx e Engels empreenderam: crítica ao conhecimento teórico, socialmente produzido até então (história, economia política, filosofia, sociologia e socialismo vulgar); investidura no necessário diálogo empírico; e análise crítica de informações produzidas por instituições oficiais sobre a classe trabalhadora. Com Marx e Engels, Thompson adotou tanto o materialismo ontológico, quanto o materialismo epistemológico imbricados ao materialismo prático.

Ao discorrer sobre a "lógica histórica", Thompson (2009) afirma que ela não pode ser submetida aos mesmos critérios da lógica analítica que busca demonstrar um experimento. A lógica do historiador, sendo de outro tipo, 


\section{Trabalhonecessário}

Issn: 1808 - 799X

ano $12, \mathrm{n}=18-2014$

necessita adequar-se ao constante movimento fenomênico, que evidencia ao mesmo tempo

manifestações contraditórias, cujas evidências particulares só podem encontrar definição dentro de contextos particulares e, ainda, cujos termos gerais de análise (isto é, as perguntas adequadas à interrogação da evidência) raramente são constantes e, com frequencia, estão em transição, juntamente com os movimentos do evento histórico: assim como o objeto de investigação se modifica, também se modificam as questões adequadas (Ibid., p. 56).

Com isto, Thompson quer dizer que a história e o processo de construção do conhecimento encontram-se em permanente processo, cujo núcleo de seu programa de pesquisa permite interrogar incessantemente o mundo em que vivemos - a realidade concreta.

São lógicas não lineares e de leis tendenciais. Como a história não é estática, trata-se, pois, de organizar conceitualmente o tempo como relação social em seus momentos e contratempos, ciclos, ritmos e crises, de modo a captar a dinâmica dos conflitos sociais por meio das discordâncias dos lapsos entre esferas econômicas, jurídicas e socioculturais.

O presente histórico por se transformar em passado (também histórico) não modifica seu status ontológico.

O passado humano não é um agregado de histórias separadas, mas uma soma unitária do comportamento humano, cada aspecto do qual se relaciona com outros de determinadas maneiras, tal como os atores individuais se relacionam de certas maneiras (pelo mercado, pelas relações de poder e subordinação, etc.). Na medida em que essas ações e relações deram origem a modificações, que se tornam objeto de investigação racional, podemos definir essa soma como um processo histórico, isto é, práticas ordenadas e estruturadas de maneiras racionais (lbid., p. 59).

É deste modo que Thompson ao apreender a classe tanto como formação socioeconômica, quanto formação cultural, captura seu processo de organização e aspectos do crescimento da consciência de classe (a consciência de uma identidade de interesses comuns entre frações da classe trabalhadora, contra os

TrabalhoNecessário - www.uff.br/trabalhonecessario; Ano 12, №18/2014. 


\section{Trabalhonecessário}

Issn: 1808 - 799X

ano 12, no $18-2014$

interesses da classe dominante) em períodos processuais e histórico dialéticos de organização social, política, econômica e cultural, apreendendo as contradições e conflitos entre capital e trabalho, em uma determinada totalidade, bem como as experiências, os costumes e as ideias da classe trabalhadora em suas relações intraclasse e, também, com a exploração e instituições burguesas.

Trata-se de um quadro ontológico materialista dialético que captura o duplo movimento entre subjetividade e objetivação. Opera na materialidade do ser, na sua consciência, na sua vontade, na sua linguagem, na sua prática e na luta que o transforma, compreendendo a especificidade de suas múltiplas determinações, no horizonte dinâmico da própria materialidade.

Eis o método do materialismo histórico dialético adotado por Thompson, que tem na história não apenas um método, mas também um processo social em sua totalidade que reúne e interrelaciona todas as histórias setoriais, tais como a história econômica, a história do trabalho, da cultura, da política, pondo em destaque a formação da classe trabalhadora por mediação daquilo que os sujeitos históricos experienciam e compartilham (THOMPSON, 2002; 2004; 2009).

Entretanto, cabe aqui uma questão: Por que Thompson quando se referia ao método cunhava-o de materialismo histórico e não materialismo histórico dialético?

Minha hipótese é a de que, Thompson (2004, p. 12), ao afirmar que não se pode entender a classe a menos que um en meno ist rico cu o processo histórico de lutas requer levar em consideração fatores sociais, culturais, experienciais, de costumes e, sobretudo, the making of the working class ${ }^{12}$, refuta um certo marxismo e seus fundamentos teóricos, particularmente o do "materialismo dialético do Partido marxista-lenista" ${ }^{13}$, liderado por Stálin.

\footnotetext{
${ }^{12} \mathrm{O}$ auto-fazer ou o fazer-se da classe trabalhadora.

${ }^{13}$ Para Josef Stalin "O materialismo histórico e dialético é chamado de materialismo dialético, porque o seu modo de abordar os fenômenos da natureza, seu método de estudar esses
}

TrabalhoNecessário - www.uff.br/trabalhonecessario; Ano 12, № 18/2014. 


\section{Trabalhonecessário}

Issn: 1808 - 799X

ano 12, no $18-2014$

Isto é, o historiador inglês evita vincular os termos histórico e dialético, simultaneamente, ao materialismo, até mesmo quando procede a "análise da dialética" (THOMPSON, 2009, p. 156-159).

Para Thompson, o método histórico e dialético do stalinismo apresentavase menos como um corpo teórico coerente do que como uma mistura de práticas repressivas, formas de domínio, retórica hipócrita, teorias errôneas e táticas leninistas derivadas da ação ilegal, que transformadas em axiomas universalistas tornaram-se as bases do oportunismo e motivos de poder estatal (ibid., p. 249).

À propósito da sumária exposição de Stálin (1938), vale ressaltar que, ao associar o materialismo histórico ao materialismo dialético por uma conjunção coordenativa aditiva, Stálin trata um como aplicação do outro e vice-versa. Resvala para o estruturalismo que tem no materialismo histórico a aplicação da dialética ${ }^{14}$ como se ela (a dialética) fosse elemento externo à história.

Ao contrário do materialismo histórico dialético adotado por Thompson, a concepção stalinista tem implicações político-analíticas que não se pode negligenciar: a história é vista como um "processo" sem sujeitos históricospolíticos e culturais. Se não há sujeitos, não há classes e, tampouco, luta de classes e consciência de classe. Neste sentido, toda ação social se apoia em dois vetores, quais sejam, o do progresso econômico e tecnológico e do evolucionismo que tem como paradigma as ciências naturais. E assim, o fim (o socialismo) justifica os meios para alcançá-lo.

Cabe ressaltar que, o materialismo histórico não repousa tranquilamente ao lado da dialética materialista esperando que esta lhe imprima movimento. Concordo, pois, com Bensaid (1999, p.15) quando afirma que, a "nova escrita" de Karl Marx - o materialismo histórico dialético - opera na dinâmica dos conflitos,

fenômenos e de concebê-los, é dialético, e sua interpretação dos fenômenos da natureza, seu modo de focalizá-los, sua teoria, é materialista" (STÁLIN, 1938).

${ }^{14}$ Cf. Stálin (op.cit.).

TrabalhoNecessário - www.uff.br/trabalhonecessario; Ano 12, № 18/2014. 


\section{Trabalhonecessário}

Issn: 1808 - 799X

ano 12, no $18-2014$

nas falhas e rupturas da discordância de tempos entre esferas econômicas, jurídicas e estéticas, destacando o papel do contratempo (a não contemporaneidade) entre estas esferas. Seu movimento se inscreve no ponto de encontro em que a herança metafísica do atomismo grego, da física aristotélica e da lógica hegeliana é submetida à prova do modelo newtoniano, do impulso das disciplinas históricas, dos desenvolvimentos impetuosos do conhecimento do ser vivo. Profundamente ancorado em seu presente, o materialismo histórico dialético excede e ultrapassa na direção do passado e do futuro.

Thompson vivenciou de forma particular essa relação dialética entre presente, passado e futuro. Com Marx e a exemplo de Marx, o historiador inglês incorpora e supera os materialismos - mecânico e umanista -, refutando a dialética idealista. Seu método de pesquisa ${ }^{15}$, se apodera da matéria nas suas particularidades, analisa as diferentes formas de desenvolvimento do fenômeno e perquiri a conexão íntima que há entre elas. O método dialético de Thompson, por fundamento, difere do método idealista.

É neste sentido que adoto a expressão materialismo histórico dialético sem a conjunção coordenativa aditiva - para o método analítico adotado por Edward P. Thompson.

\section{Categorias de análise: por um diálogo com a empiria}

Resgatar as categorias analíticas desenvolvidas por Edward Thompson, tais como classe social e de seus correlatos luta de classes e consciência de classe, cultura e experiência, expressa o mergulho no debate em torno dos estudos culturais, que busca marcar determinada posição no que diz respeito à atualizada pertinência do emprego daquelas categorias nas investigações acerca

${ }^{15}$ Aqui, parafraseio MARX (2004, p. 26-29).

TrabalhoNecessário - www.uff.br/trabalhonecessario; Ano 12, № 18/2014. 


\title{
Trabalhonecessário
}

Issn: 1808 - 799X

ano 12, no $18-2014$

das sociedades contemporâneas, tendo por base o materialismo histórico dialético.

Com Marx e Engels, Thompson rediscute o conceito de classe e o emprega de forma criativa. Por meio da noção de experiência, busca um nexo entre o modo de produção e formação da consciência de classe, bem como seus condicionantes e constituintes, em termos culturais e de valores morais (MATTOS, 2012, p. 85-86).

Neste sentido, não ignora a importância da herança protestante e democrático-burguesa; considera a influência da economia política capitalista como ideologia autêntica e articulada; não se descura das contribuições dos cientistas naturais britânicos e, tampouco, dos estilos de vida - hábitos e costumes, como as feiras, as canções folclóricas, etc. - da classe trabalhadora. Discorda, por completo, do uso esquemático de classe social e da ideia de burguesia apática e do operariado mecanicamente a ela subordinado (THOMPSON, 2007, p. 118); recusa, também, o uso esquemático do conceito gramsciano de hegemonia.

\begin{abstract}
Com a preocupação de inserir a cultura na arena da luta de classes, o historiador inglês encontrou sua melhor inspiração em um conceito desenvolvido por Antonio Gramsci: hegemonia. Afinal o desafio a que se propunha era justamente o de tentar desvelar manifestações da luta de classes no contexto pré-capitalista, o que o levava a estudar tanto as estratégias político-ideol gicas que sedimentavam a dominação de classes - o paternalismo - quanto as mani estações da resistência dos subalternos, ainda que não sistematizadas em termos de uma consciência madura (MATTOS, 2012, p. 196).
\end{abstract}

No que diz respeito aos estudos culturais, parto do presente histórico, em que farta documentação tem sido emanada dos programas de pós-graduação, por meio de pesquisas, seminários, conferências e, ainda, editoras dedicam catálogos inteiros à produção de estudos sobre cultura. Na realidade, esses estudos fazem parte de um movimento de intelectuais, autodenominados pós-modernos, e de um 


\section{Trabalhonecessário}

Issn: 1808 - 799X

ano 12, no $18-2014$

projeto maior que se propõe, com crescente sucesso, a remodelar o ensino e a pesquisa na área das ciências humanas e sociais.

Longe de serem um grupo homogêneo, os pós-modernos de direita, por um lado, crêem no poder democratizante e humanizador do capitalismo, bem como nos prazeres trazidos pelo consumismo, proclamando o fim da História ou o triunfo do capitalismo diante da queda do Muro de Berlim. De outro lado, os intelectuais da esquerda pós-modernista ${ }^{16}$ repetem o discurso do fim de época e o nascimento de tempos, que marcariam o fim do lluminismo, dos velhos princípios de racionalidade e de antigas verdades e ideologias. O paradigma emergente possibilitaria a construção de um mundo melhor com base na harmonia entre Estado, mercado e comunidade.

Segundo Wood (1999), os intelectuais pós-modernos revelam descaso pela história, desconsiderando as crises estruturais do capitalismo ocorridas desde a Era de Ouro ${ }^{17}$, o que os impede de produzir uma teoria crítica, porquanto alguns entendem que as oportunidades de oposição ao capitalismo são fortemente limitadas; outros sequer vislumbram alguma possibilidade de mudança no "sistema capitalista" pelo fato de não o apreendem como totalidade social ou ao menos entendem o que seja sistema (Ibid. p.15-6).

A concepção pós-moderna de conhecimento científico parte do pressuposto de que o projeto do lluminismo teve tanto sucesso quanto fracasso: a "racionalização" da organização social e política, o determinismo do progresso científico de tecnológico, a democratização da educação seriam expressão de fatos bem sucedidos da modernidade. Entretanto estes progressos teriam pouco contribuído para aumentar a "racionalidade essencial" (ou a ação comunicativa) dos seres humanos impedindo, assim, a liberdade humana. A "racionalização" e a burocracia, manifestações do imperialismo, de opressão e de colonização do

\footnotetext{
16 Wood (1999, p. 11) emprega o termo pós-modernista para designar uma vasta gama de tendências intelectuais e política, incluindo o pós-marxismo e o pós-estruturalismo.

17 HOBSBAWM, 2005.
}

TrabalhoNecessário - www.uff.br/trabalhonecessario; Ano 12, № 18/2014. 


\section{Trabalhonecessário}

Issn: 1808 - 799X

ano 12, no $18-2014$

mundo da vida são marcas de uma época. Neste sentido, o marxismo, ao longo do século XX, com seu ideal revolucionário e determinista teria produzido os mais variados tipos de opressão, bem como deslegitimado a reivindicação das minorias (grupos feministas, étnicos, gays, lésbicas, religiosos, regionais, etc.) com seu método rígido e pressupostos metateóricos que privilegiam a economia, usando categorias gerais, como modo de produção e classe social.

Buscando se libertar da suposta opressão do método totalizante, a ênfase da esquerda pós-modernista recai na visão fragmentada de mundo e de ceticismo epistemológico, interessando-se por temas vinculados à linguagem, ao discurso e à "cultura", nos quais tanto os su eitos ist ricos, quanto as relações sociais são construídos no e pelo discurso ${ }^{18}$.

Para os pós-modernos, a centralidade das relações sociais está na língua. Insistem na pluralidade de formações de poder-discurso (Foucault) ou de jogos de linguagem (Lyotard). Ora, se os sujeitos encontram-se subsumidos à língua, não existe, fora dos discursos, nenhuma outra verdade e tampouco referencial teórico que não seja o dos discursos. Portanto, esquemas interpretativos da realidade concreta, como os produzidos por Marx e Freud, tidos como totalizantes, são invalidados.

As implicações políticas desta visão fragmentada de mundo e de produção do conhecimento, com bases em subculturas, se manifestam na impossibilidade de qualquer política emancipadora que: (i) tenha por base a solidariedade e a ação coletiva, (ii) pressuponha a formação da identidade de classe ou de experiência comum ou, ainda, de interesses comuns, (iii) busque qualquer tipo de mobilização global. Daí o esforço realizado no sentido de destruir a categoria revolução enquanto objeto de análise, buscando demonstrar que as revoluções são grandes equívocos. A revolução passa a ser confundida com eventos do

${ }^{18}$ Cf. SANTOS, 2000; 2002.

TrabalhoNecessário - www.uff.br/trabalhonecessario; Ano 12, № 18/2014. 


\section{Trabalhonecessário}

Issn: 1808 - 799X

ano 12, no $18-2014$

cotidiano, como festa, ritual ou cultura, ao mesmo tempo em que é descaracterizada como revolução social (CARDOSO, 2005, p. 84).

Conceitos como democracia substituem o de revolução; movimentos e sujeitos sociais deslocam o conceito de classe e seu correlato luta de classes; a terceira via substitui a possibilidade de as classes sociais construírem um modo de produção e reprodução da existência diferente do determinado pelo sistema capitalista; o conceito de Estado cede lugar para setor público, enquanto o imperialismo fica ofuscado pela globalização ou, quando menos, escamoteado pela categoria império de Negri e $\mathrm{Hardt}^{19}$. Qualquer política que se volte contra o poder de Estado e da classe dominante é vista como, excessivamente, totalizante ou universalista 20 .

O pós-modernismo, ao condenar as metanarrativas, cede espaço para análises que destacam o papel da cultura e de uma ação política baseada em diferenças de identidade. É um ponto de vista que envereda pelo determinismo cultural relativista $^{21}$, cuja realidade estudada só é explicável através do particularismo de diferenças culturais.

A despeito de um número considerável de intelectuais alegar que sua crítica em matéria de cultura é socialmente subversiva, eles consideram vulgares trabalhos que vinculam à teoria a luta política. Trata-se de dissolver a política na cultura, de modo que esta é transformada em instrumento de reivindicação dos diretos humanos, em geral, e dos direitos culturais particulares. Assim entendida, a cultura seria capaz de abrir canais para as minorias expressarem suas identidades e exercerem sua palavra e ação, reconhecidas como legítimas no espaço publico.

Esta concepção restrita de política e de cultura apoia-se, muitas vezes, nos estudos culturais de marxistas, como Antonio Gramsci, Edward Thompson e

\footnotetext{
${ }^{19}$ Cf. BORON, 2002.

20 Para maiores detalhes, ver HARVEY, 2005, p. 50.

${ }^{21}$ Para uma análise do determinismo e relativismos culturais ver SPIRO, 1998.
}

TrabalhoNecessário - www.uff.br/trabalhonecessario; Ano 12, № 18/2014. 


\section{Trabalhonecessário}

Issn: 1808 - 799X

ano 12 , no $18-2014$

Raymond Williams, apartando por completo o conteúdo revolucionário que perpassa suas obras.

No início do século XX, Gramsci volta-se para os temas da cultura, seja nas questões relacionadas ao papel do intelectual, à construção do consenso e de hegemonia; seja na análise do Americanismo e fordismo como modo de organização da produção, que, refletindo em todas as dimensões da sociedade, engendra uma cultura peculiar à transformação técnico-econômica requerida por aquele modelo de produção.

Atento à relação entre ideias, dominação e transformação econômica e sociocultural, o marxista italiano empreende uma análise inteiramente nova da cultura e da literatura popular. Estuda tanto os seus gêneros (o melodrama, o folhetim, o romance policial, o romance de suspense), quanto os instrumentos de produção e difusão da cultura (jornais, revistas, anuários, almanaques), bem como obras de grande circulação, formando um conjunto que deveria ser entendido como um problema político e explicitamente teorizado em relação ao seu papel na manutenção ou subversão da ordem social.

$\mathrm{Na}$ es era da cultura, aliás, as 'explosões'22 são ainda menos freqüentes e menos intensas do que na esfera da técnica, na qual uma inovação se difunde, pelo menos no plano mais elevado, com relativa rapidez e simultaneidade. Confunde-se a 'explosão' de paixões políticas acumuladas num período de transformações técnicas, às quais não correspondem novas formas de organização jurídica adequada, mas sim imediatamente certo grau de coerções diretas e indiretas, com transformações culturais, que são lentas e graduais; e isto porque, se a paixão é impulsiva, a cultura é produto de uma complexa elaboração. (A referência ao fato de que por vezes, o que se tornou 'erro vel o' na cidade ainda é 'utensílio na província pode ser desenvolvida com utilidade) (GRAMSCI, 2001, v.2, p. 207).

Contudo, Gramsci não é um culturalista porquanto vê a cultura popular como folclore da filosofia, do mesmo modo que, manifestação do senso comum

\footnotetext{
22 Gramsci faz referência às modificações no modo de pensar, nas crenças, nas opiniões que, não explodem espontaneamente, mas ocorrem gradual e lentamente, por meio de "combinações sucessivas" de coerção e produção de consenso, por meio de material ideol gico.
}

TrabalhoNecessário - www.uff.br/trabalhonecessario; Ano 12, №18/2014. 


\section{Trabalhonecessário}

Issn: 1808 - 799X

ano 12, no $18-2014$

que se apresenta de inúmeras formas, contraditórias e fragmentadas. "Seu traço fundamental e característico é o de ser uma concepção (inclusive nos cérebros individuais) desagregada, incoerente, inconsequente" (GRAMSCI, 2001, v.1, p. 114).

Com isto, Gramsci quer dizer que a cultura popular não contribui, por si só, para a criação de uma nova cultura ou, até mesmo, de um novo paradigma de ciência capaz de difundir criticamente seu conhecimento e descobertas, no sentido de promover uma transformação de ordem intelectual e moral, com vistas à revolução (Ibid., p.95-6).

Já mencionei que, o movimento da New left, do que Edward Thompson, Raymond Williams e Richard Hoggat participaram ativamente, foi espaço histórico de inflexão no pensamento de esquerda na Grã-Bretanha ao incorporar à crítica da economia política o espectro cultural. O emprego do conceito de cultura, seja no sentido em que Raymond Williams operou com o materialismo cultural, contribuindo para uma teoria materialista da cultura, seja no sentido de Edward Thompson que, ao alargar a ênfase tradicional da historiografia marxista em história econômica, salienta o modo de vida da classe trabalhadora, seus hábitos, esperanças e experiências compartilhadas, bem como apresenta um entendimento que transcende as discussões até então travadas no interior da critica cultural (CEVASCO, 2008).

A gênese dos estudos culturais encontra-se no seio da Worker's Educational Association $(W E A)^{23}$, onde Thompson, Williams e Hoggart ministravam aulas, no turno da noite, para trabalhadores, o que propicia a formulação de uma teoria e análise da cultura que se valha da relação entre ser social e consciência social (produzida a partir do mundo real das relações de produção e reprodução da vida dos alunos).

${ }^{23}$ Associação para a Educação universitária de Trabalhadores.

TrabalhoNecessário - www.uff.br/trabalhonecessario; Ano 12, № 18/2014. 


\section{Trabalhonecessário}

Issn: 1808 - 799X

ano 12 , no $18-2014$

A partir de atividades didático-pedagógicas que buscavam superar o modelo tradicional de educação, empregando palavras-chave como experimentalismo, interdisciplinaridade e envolvimento político, os três marxistas modificam o ensino da arte e literatura dando-Ihe um cunho sócio-histórico e cultural. Esta abordagem, que mais tarde propiciaria a criação da Escola de Estudos Culturais ${ }^{24}$, trata de questionar as formulações centradas "na alta cultura", em um contexto de expansão da indústria cultural.

É neste sentido que, tanto para William, quanto para Thompson, a dimensão cultural denota campo de luta social e política, de disputas e tensões, de afirmação de valores e significados existentes que se manifestam em "organizações alternativas ou contestadoras", por exemplo, de associações, sindicatos e partidos por parte da produção cultural dos trabalhadores (WILLIAMS, 208, p. 224).

$O$ conceito de cultura encontra-se intimamente relacionado às experiências dos sujeitos históricos em determinada formação socioeconômica. Isto quer dizer que, "os en menos sociais e culturais não correm atrás dos econ micos, ap $\mathrm{s}$ longa demora; estão na sua origem, imersos no mesmo nexo relacional" (THOMPSON, 2007, p. 167).

Ao analisar A formação da classe operária inglesa, Thompson (2004) ressalta que a classe "precisa estar encarnada de pessoas e contextos reais", e

24 A Escola de Estudos Culturais ou Escola de Birmingham teve origem no Centre for Contemporaty Cultural Studies da Universidade de Birmingham, no ano de 1964 - o primeiro programa de pós-graduação em estudos culturais, tendo como referências a publicação das obras já mencionadas, aqui, na nota $\mathrm{n}^{\circ} \mathrm{11}$. A referida Escola manteve uma crítica sistemática, refutando a ideia de cultura como manifestação autônoma da subjetividade em relação ao ser social, até a sua transferência para os Estados Unidos. Com a afirmação do neoliberalismo, por meio do Consenso de Washington, a Escola reformula seu conteúdo sob a perspectiva fragmentada pósmoderna, dando origem ao multiculturalismo, que passa a exercer influência marcante na América Latina (VALENCIA, 2008). 


\section{Trabalhonecessário}

Issn: 1808 - 799X

ano 12 , no $18-2014$

que, portanto, ela se orma somente "quando alguns omens, como resultado de experiências comuns (herdadas ou partilhadas), sentem e articulam a identidade de seus interesses entre si, e contra outros omens, cu os interesses di erem". Se a experiência de classe é determinada, em grande medida, pelas relações de produção em que os omens nasceram, ou entraram involuntariamente, "a consciência de classe, [ao contrário, será construída], sendo a forma como essas experiências são tratadas em termos culturais: encarnadas em tradições, sistemas de valores, idéias e ormas institucionais" (Ibid., p. 10).

Nesse processo de resgate, a categoria experiência torna-se mediação na análise de Thompson, que com foco na dimensão cultural reconstitui modos de comportamentos, condutas e costumes na sua relação com a cultura, em perspectiva de classe, histórica e geograficamente datados. A experiência, em Thompson, longe de reduzir a análise ao micro e ao local, denota tempo ${ }^{25}$, imprimindo à classe uma dimensão histórica. A classe trabalhadora é uma formação tanto social e cultural, quanto econômica, possuindo identidade de interesses contra seus dirigentes e empregadores (Ibid., p 12-3).

Ressalte-se que uma classe social, em tempo algum, é culturalmente monolítica. Quanto a esse e outros aspectos, Williams (2008) elucida que determinados grupos dentro de uma classe podem estar subindo ou descendo de importância, segundo o desenvolvimento geral da classe e da sociedade. Além disso, determinados grupos intraclasse podem ter filiações culturais, religiosas, alternativas, que não são características da classe como um todo, bem como formas diferenciadas de trabalho, que no entanto contribuem para existência de variações na produção cultural (lbid., p. 74).

\footnotetext{
${ }^{25}$ Refiro-me ao tempo histórico, ao tempo que não se fecha na temporalidade do presente, mas, sim, leva em consideração o tempo da conjuntura histórica e dos indivíduos singulares, bem como do tempo infinito da humanidade. Tempo este que incorpora a dinâmica das relações sociais, dos conflitos e contratempos entre as esferas econômicas, jurídicas e estéticas.
} 


\section{Trabalhonecessário}

Issn: 1808 - 799X

ano 12, no $18-2014$

Thompson, a exemplo de Williams, aponta também para a aparente diversidade entre as culturas individuais como parte do todo; parte de uma experiência comum que diz respeito às formas de exploração, simultaneamente, econômicas, morais e culturais. Isto quer dizer que a exploração não é apenas uma categoria de análise econômica mas, sobretudo, uma realidade, vivenciada pelos que experimentam a exploração, seja como produtores, seja como consumidores.

Os argumentos supracitados permitem-me afirmar com Wood (1999) que, o enfoque materialista dialético da história não refuta ou denigre as dimensões culturais da experiência humana. Ao contrário, a compreensão materialista dialética é um passo essencial para libertar a cultura do confinamento capitalista que penetra em todas as dimensões da vida social e do ambiente natural, transformando tudo quanto pode em mercadoria.

A compreensão materialista da história não nega a importância de outras identidades além da de classe, das lutas contra a opressão sexual e racial, ou das complexidades da experiência humana em um mundo instável e mutável como o nosso, onde as solidariedades são frágeis e incertas; não ignora o ressurgimento de identidades, na qualidade de nacionalismo, fascismo, etc., como forças históricas poderosas e destrutivas; não desconsidera que a reestruturação do capitalismo transformou a composição da classe trabalhadora; não rebate o argumento de que existem divisões raciais e sexuais intraclasse trabalhadora; muito menos contesta que o imperialismo ideológico e cultural reprime a multiplicidade dos valores e culturas humanos ou, tampouco, nega a importância da língua e da política cultural em um mundo tão dominado por símbolos, imagens e comunicação de massa.

TrabalhoNecessário - www.uff.br/trabalhonecessario; Ano 12, № 18/2014. 


\section{Trabalhonecessário}

Issn: 1808 - 799X

ano 12, no $18-2014$

\section{Classe, experiência e cultura: trilhas thompsonianas para investigar fenômenos educacionais}

Ao longo do texto busquei evidenciar que, Thompson ao optar pela lógica da histórica como um movimento processual, busca a objetividade do conhecimento histórico e da verdade, tomando caminho oposto ao idealismo subjetivista e ao materialismo mecanicista, o que requer do pesquisador desempenhar um papel ativo no processo de construção do conhecimento histórico, cuja objetividade contém sempre uma dose de subjetividade.

Marx, nas Teses sobre Feuerbach, chama a atenção para esta relação cognitiva entre sujeito e objeto, que agem mutuamente: "o principal de eito de todo materialismo (inclusive o de Feuerbach) é apreender o objeto, a realidade e o mundo sensível sob a forma de objeto ou de intuição, não como atividade humana sensível, enquanto práxis, de maneira não sub etiva" (...) desconsidera, portanto, "a sensibilidade como atividade prática umana e sensível" (Teses sobre Feuerbach: $1^{\underline{a}}, 3^{\underline{a}}, 5^{\underline{a}}$ e $8^{\underline{a}}$ Teses, in: MARX e ENGELS, 2002).

Com efeito, a adoção do método do materialismo histórico dialético, em que o sujeito possui papel ativo, a pesquisa tem diversas implicações, tais como: a adoção da visão de mundo a partir da perspectiva da classe trabalhadora; a ênfase na dinâmica das relações sociais; a reconstrução histórica do objeto, evidenciando as contradições e mediações em uma dada totalidade, de modo a buscar a aproximação do real (da verdade); a visão do conhecimento, da história e da verdade e, por conseguinte, do objeto de estudo, como processos em permanente construção.

Tomando a educação como campo empírico e se partimos da consideração de que as instituições de ensino e as reformas educativas são produzidas em meio das relações de poder e de classe, geradoras de embates de concepções de sociedade, de trabalho e de cultura; se apreendemos a

TrabalhoNecessário - www.uff.br/trabalhonecessario; Ano 12, № 18/2014. 


\section{Trabalhonecessário}

Issn: 1808 - 799X

ano 12 , no $18-2014$

escola/universidade como espaço privilegiado não apenas de produção e transmissão do conhecimento, mas também de formação para o trabalho simples, trabalho intelectual e trabalho complexo; se captamos a "improdutividade da escola improdutiva" 26 , nossa ação, entendida aqui como práxis educativa/práxis política, não será apenas o trabalho docente, em geral, mas algo realizado no sentido de criar uma "nova cultura"27.

Desse modo, adentramos, com Thompson (2009, p. 233-4), na "experiência histórica", ao mesmo tempo em que reexaminamos a totalidade densa e complexa na qual a vida familiar, institucional (particularmente a escolar/universitária) e social se estruturam e a consciência social encontra realização e expressão.

Parentesco, costumes, as regras visíveis e invisíveis da regulação social, hegemonia e deferência, formas simbólicas de dominação e resistência, fé religiosa e impulsos milenaristas, maneiras, leis, instituições e ideologias - tudo o que em sua totalidade, compreende a 'genética' de todo processo histórico, sistemas que se reúnem todos, num certo ponto, na experiência humana comum, que exerce ela própria (como experiências de classe peculiares) sua pressão sobre o conjunto (Ibid., p. 234. Itálico do autor).

Neste sentido, as categorias analíticas desenvolvidas por Thompson podem abrir um leque de possibilidades para a luta em torno dos projetos educacionais, societários e culturais, sem, no entanto, descurarmos dos clássicos. O historiador inglês oferece pistas para a crítica à manipulação da legislação, dos meios de comunicação, formação e propaganda, do aparelho repressor policialesco em favor da manutenção da ordem vigente, bem como dos procedimentos institucionais que solapam o conhecimento histórico, socialmente produzido, da classe trabalhadora.

\footnotetext{
${ }^{26}$ Para uma análise crítica da visão reprodutivista de escola, ver FRIGOTTO, 1981.

27 Para Gramsci (1978), a "nova cultura não significa apenas fazer individualmente descobertas 'originais'; significa também e, sobretudo, difundir criticamente verdades já descobertas, 'socializálas' e transformá-las em base de ações vitais, em elemento de coordenação e de ordem intelectual e moral".
}

TrabalhoNecessário - www.uff.br/trabalhonecessario; Ano 12, №18/2014. 


\section{Trabalhonecessário}

Issn: 1808 - 799X

ano 12, no $18-2014$

$\mathrm{Na}$ análise do fazer-se da classe trabalhadora, Thompson volta-se também para os níveis de escolarização dos trabalhadores, refutando por completo a ideia de verdadeira ou falsa consciência. Para Thompson (2007, p. 279), uma classe não pode existir sem um tipo qualquer de consciência de si mesma. Ela (a classe) "não é uma motocicleta cujo assento esteja vazio e do que os intelectuais, saltando sobre ele, assumem a direção" (Ibib., p. 281).

Ao contrário, a classe se delineia segundo o modo como os homens e mulheres vivem e experienciam suas relações de produção e reprodução da vida, segundo situações determinadas, no interior do 'conjunto de suas relações sociais' (Ibid., p. 277), do que a educação e os processos de escolarização fazem parte. Daí as contribuições do historiador inglês para se refletir não apenas sobre os fenômenos educacionais, mas também analisá-los criticamente nos dias que correm.

Em um contexto em que o fenômeno da "contrarreforma" (GRAMSCI, 2002, p. 143-4) educativa - do espaço-tempo e cultura escolar, dos currículos e, como não poderia deixar de ser, administrativa e pedagógica - vem operando, além da contradição fundamental capital e trabalho, na contradição tomadas de decisão autoritárias e estratégias de construção de obtenção do consenso, ela configurase mais como uma reforma produzida a partir do "alto", de modo a impulsionar a cultura dominante, do que aquela que levaria em consideração a experiência dos verdadeiros protagonistas do espaço escolar (docentes, técnico-administrativos, estudantes, pais, mães e responsáveis).

Sendo assim, é possível vislumbrar o espaço escolar/universitário como espaço de luta política, de organização e de formação da classe trabalhadora, em sua relação mútua com a formação da consciência (crítica) de classe, na direção contra-hegemônica.

Isto quer dizer que, buscar entender, nos dias que correm, o processo de formação da classe trabalhadora, empregando as categorias analíticas

TrabalhoNecessário - www.uff.br/trabalhonecessario; Ano 12, № 18/2014. 


\section{Trabalhonecessário}

Issn: 1808 - 799X

ano 12, no $18-2014$

thompsonianas, é uma possibilidade de apreender, além das "peculiaridades" da classe, as experiências que emergem dos conflitos entre e intraclasses e as suas tradições de luta. É, também, concentrar-se na análise de suas atitudes e posicionamentos, bem como na maneira como vêm se organizando em relação às formas autoritárias de tomadas de decisão do bloco no poder.

No caso particular do campo educacional, trata-se de analisar as modificações pelas quais vem passando a cultura escolar; as práticas docentes; as relações professor-aluno; as relações entre docentes e grupos gestores; as experiências dos profissionais da educação, em geral, na adoção de modelos e propostas educacionais que têm na educação um serviço passível à comercialização; as manifestações nas associações e sindicatos.

Todos estes elementos podem descortinar os movimentos oscilatórios do processo de formação da consciência de classe, os interesses, as experiências sociais, os costumes e os valores que acabam por definir as estratégias de resistência ao projeto hegemônico de sociedade; podem, também, revelar os costumes que mobilizam a fração da classe trabalhadora em torno da educação, em geral, do espaço-tempo-cultural escolar e dos processos de escolarização, em particular.

Inserir estes elementos de análise em um contexto socioeconômico, político, educacional e cultural, pode contribui para a apreensão não apenas das formas de comportamento no cotidiano escolar, mas também de seus nexos com valores, padrões de consumo e de lazer, etc. Afinal, "quando uma pessoa [profissional da educação, estudante, pai, mãe] se junta ou atravessa um piquete grevista, está fazendo uma pequena escolha de valores, mesmo que os termos da escolha e parte daquilo que a pessoa escolhe sejam social e culturalmente determinados" (THOMPSON, 2009, p. 240).

TrabalhoNecessário - www.uff.br/trabalhonecessario; Ano 12, № 18/2014. 


\section{Trabalhonecessário}

Issn: 1808 - 799X

ano 12 , no $18-2014$

Por esta razão, a importância do emprego das categorias de experiência e de cultura como parte da produção do conhecimento sobre os fenômenos educacionais,

já que a experiência é um termo médio necessário entre o ser social e a consciência social: é a experiência (muitas vezes a experiência de classe) que dá cor à cultura, aos valores e ao pensamento: é por meio da experiência que o modo de produção exerce uma pressão determinante sobre outras atividades: e é pela prática que a produção é mantida (THOMPSON, 2009, p. 139).

Se a cultura é compreendida como: (i) formação tecida não apenas pelas classes sociais, mas também por outras determinações sociais não-classistas como nacionalidade e espaço demográfico, religião, cor, gênero e idade; (ii) terreno que abarca desde as relações de produção e reprodução tecnoeconômicas até as representações de mundo com suas normas éticas e jurídicas, seus costumes, tradições e ideologias; parte dos processos de comunicação e formas de organização social e política, dos quais a educação e de forma particular a escola/universidade com seus processos de escolarização fazem parte; então, a experiência e a cultura "são um ponto de junção" (lbid.), são duas metades que se completam.

Pois as pessoas não experimentam sua própria experiência apenas como ideias, no âmbito do pensamento e de seus procedimentos, ou (como supõem alguns praticantes teóricos) como instinto proletário, etc. Elas também experimentam sua experiência como sentimento e lidam com esses sentimentos na cultura, como normas, obrigações familiares e de parentesco, e reciprocidades, como valores ou (através de formas mais elaboradas) na arte ou nas convicções religiosas. Essa metade da cultura ( e é uma metade completa) pode ser descrita como consciência afetiva moral (lbid., p. 234).

Esta assertiva oferece a possibilidade de se avançar no exame das implicações da escola/universidade, em geral, e dos processos de escolarização, em particular, na cultura. Dentre outros autores, Silveira $(2011$; 2012) aponta para as manifestações da relação imperialismo e dependência (econômica, 


\section{Trabalhonecessário}

Issn: 1808 - 799X

ano 12, no $18-2014$

tecnológica, educacional e cultural) na sociedade brasileira, tendo por mediações principais os organismos supranacionais e o Estado.

Funcionando como mecanismo de interpenetração e desdobramento dos conteúdos políticos, econômicos e culturais do imperialismo, os organismos supranacionais, mediados pelos Estados-Nações, burguesias locais e outros intelectuais, assumem papel decisivo nas orientações de ordem política, assistência técnica, metodológica e financeira no que diz respeito ao desenvolvimento econômico, à modernização, reestruturação produtiva, democratização do Estado-Nação e democratização da educação, com vistas à reforma cultural, intelectual e moral da sociedade (lbid., ibid.).

Sob as bandeiras da "inclusão social", do "combate à pobreza" e do "combate às desigualdades na educação", busca-se afirmar o capitalismo como um modo de relação social e produção insuperável, escamoteando, assim, o antagonismo entre classes (lbid., ibid.).

No que mais nos interessa, a cultura popular vem sendo apropriada, pelos organismos supranacionais e empresariado, segundo o que Williams (2008) considera uma complexa combinação de elementos que produzem e reproduzem as condições de vida em um campo de conflitos, cultural e social, na direção de uma universalidade burguesa.

Cabe lembrar, com Thompson, que a cultura denota conflito. Neste sentido, a escola/universidade, por ser mediação tanto da classe trabalhadora quanto do capital, pode ser vista como arena desta luta, onde seus protagonistas históricos tomam parte, seja por coerção e consentimento, seja por resistência na direção contra-hegemônica. Trata-se, pois, de capturar a cultura em um campo contraditório nas suas relações de classe.

Se de um lado, o fenômeno da democratização do acesso à educação possibilita a cultura popular irromper o espaço escolar/universitário e, ainda que, sob a incapacidade de os imperativos educacionais lidar com as diferenças, a

TrabalhoNecessário - www.uff.br/trabalhonecessario; Ano 12, № 18/2014. 


\section{Trabalhonecessário}

Issn: $1808-799 X$

ano 12, no $18-2014$

cultura dos pobres avança nos processos de escolarização; de outro, as especificidades culturais são tidas como subsetores econômicos que geram renda, estimulam o desenvolvimento local e incentivam a criatividade, fortalecendo, assim, setores do ramo empresarial, como o do turismo, do agronegócio, da propaganda e marketing, etc.

Desta perspectiva, a política de valorização e de incorporação da cultura popular aos ditames do capital, busca produzir, no meio popular, valores de uma nova cultura cívica baseada no regime de colaboração de classes e na ética empresarial.

É neste terreno movediço das contradições entre capital e trabalho, trabalho e educação, controle, produção e consumo, que ocorre o processo de formação da consciência da classe trabalhadora. É no meio das vontades individuais e autoconscientes de suas experiências que, homens e mulheres fazem-se (no sentido de formação), por mais particulares que sejam as suas condições de vida material e as circunstâncias em que vivem e partilham suas experiências (THOMPSON, 2009, p. 138).

Para o historiador inglês não existe período histórico de atrofia intelectual, até mesmo "quando a educação formal de grande parte do povo se resume a ler, escrever e contar". A partir de sua experiência própria, recorrendo à sua instrução arduamente obtida, mesmo sendo de baixa qualidade, "os trabalhadores podem se organizar politicamente e formar uma nova consciência [crítica] em relação aos seus interesses e à sua situação enquanto classe (lbid., 2002, p. 304).

Nutre-se, aqui, mais outro(s) objeto(s) de estudo que, a partir das contribuições de Thompson, venha(m) a considerar: (i) o movimento interno da escola inscrito no movimento dinâmico e histórico de reformas educacionais, cultural, intelectual e moral da sociedade; (ii) a análise da memória individual e coletiva dos sujeitos históricos que ocupam o cotidiano escolar/universitário e que buscam a construção de uma identidade institucional e de seu próprio projeto

TrabalhoNecessário - www.uff.br/trabalhonecessario; Ano 12, № 18/2014. 


\section{Trabalhonecessário}

Issn: 1808 - 799X

ano 12, no $18-2014$

político-pedagógico; (iii) as discussões e estudos produzidos no seio das organizações da classe trabalhadora (associações, federações, sindicatos, partidos políticos) que buscam, a partir de sua cultura, de experiências partilhadas e de valores coletivistas, a formação de uma consciência crítica das relações de produção e reprodução da vida ampliada, a universalização dos direitos sociais subjetivos, bem como a socialização do conhecimento historicamente produzido.

\section{À guisa de conclusão}

Ao recuperar o pensamento de Edward $P$. Thompson, desaguamos em uma preleção sobre o duplo trabalho crítico do pesquisador, aliás, uma preocupação marcante nos textos do historiador inglês, que convida a refletir e a analisar a realidade concreta, com categorias históricas e analíticas, vista a partir "de baixo".

O levantamento bibliográfico, bem como a crítica ao conhecimento teórico, produzido pela "tradição marxista"; a investidura no necessário diálogo empírico; e a análise crítica de documentos oficiais, jornais, panfletos, debates políticos, registros de entidades de classe e de objetos de memórias de indivíduos singulares, realizados por Thompson, foge ao esquema interpretativo que, muitas vezes, tenta vestir a empiria com a teoria.

Seu caminho percorrido na análise e forma de exposição desvelam as determinações concretas do objeto, evidenciando sobretudo a atualidade do método do materialismo histórico dialético. À medida que percorremos as trilhas thompsonianas encontramos terra firme para a análise dos fatos históricos e 0 necessário estímulo para prosseguir na investigação dos fenômenos sociais, particularmente dos educacionais.

TrabalhoNecessário - www.uff.br/trabalhonecessario; Ano 12, № 18/2014. 


\section{Trabalhonecessário}

Issn: 1808 - 799X

ano 12, no $18-2014$

Para Thompson (2007, p. 133-5), a história é composta de episódios. Se não pudermos adentrá-los, não poderemos, então, adentrar a história real, que se revela, somente, depois de árdua pesquisa.

Por esta razão, o historiador inglês ressalta a necessidade de se compreender o contexto internacional e imperialista e o ressurgente nacionalismo, cujo clima político-cultural "contamina profundamente as massas", o que, aliás, tem sido negligenciado pelos pesquisadores da esquerda marxista (Ibid., p. 135)

A atualidade de seu pensamento se evidencia quando aponta, já naquela época, para a manifestação do imperialismo no seio mesmo do movimento operário e seus desdobramentos na política de esquerda que assume a tarefa do possível (Ibid., p. 137-8). É claro que, estas manifestações têm implicações políticas na cultura, na experiência dos indivíduos singulares na formação da consciência de classe que, permanentemente em seu processo, sofre oscilações; e, como não poderia deixar de ser, no campo educacional.

Entretanto, o que torna a trilha thompsoniana instigante é o fato de que à análise de todos aqueles acontecimentos históricos não escapa o olhar da classe como processo encarnado de homens e mulheres que, diferentes entre si, têm costumes e relações que se alteram, tanto entre si como em contato com outros grupos sociais.

Para concluir, entendo que a necessária crítica, no sentido da práxis revolucionaria, é aquela que investiga a totalidade social, capturando suas contradições e mediações na e da manifestação dos fenômenos sociais, em geral, e educacionais, em particular. A análise do desenvolvimento do modelo de escola moderna que, com seus entraves próprios à sociedade de classe, se inscreve na dinâmica histórica da expansão da produção e do mercado mundial capitalistas, tem muito a ganhar de densidade teórico-metodológica na medida em que incorporar as contribuições de Edward Thompson, particularmente no 


\section{Trabalhonecessário}

Issn: 1808 - 799X

ano 12, no $18-2014$

emprego das categorias de classe social, formação da consciência de classe, cultura e experiência.

\section{Referências}

BARATA-MOURA, José. Materialismo e subjectividade. Estudos em torno de Marx. Lisboa: Edições "Avante!", 1997.

BENSAID, Daniel. Marx, o intempestivo: grandezas e misérias de uma aventura crítica (séculos XIX e XX). Rio de Janeiro: Civilização Brasileira, 1999.

BORON, Atílio. Império \& imperialismo: uma leitura crítica de Michael Hardt e Antonio Negri. Buenos Aires: CLASO, 2002.

CARDOSO, Ciro Flamarion. Um historiador fala de teoria e metodologia: ensaios. Bauru, S.P: EDUSC, 2005.

CEVASCO, Maria Elisa. Dez lições sobre estudos culturais. São Paulo: Boitempo, 2008.

CIAVATTA, Maria. A memória do trabalho e da educação. In: CIAVATTA, Maria (Org.). Memória e temporalidades do trabalho e da educação. Rio de Janeiro: Lamparina: FAPERJ, 2007.

FRIGOTTO, Gaudêncio. A produtividade da escola improdutiva: um (re) exame das relações entre educação e estrutura econômico-social e capitalista. 7. ed. São Paulo: Cortez, 2001.

FRIGOTTO, Gaudêncio; CIAVATTA, Maria; RAMOS, Marise. A gênese do Decreto no 5.154/2004: um debate no contexto controverso da democracia restrita. In: FRIGOTTO, Gaudêncio; CIAVATTA, Maria; RAMOS, Marise. Ensino médio integrado: concepções e contradições. São Paulo: Cortez, 2005.

GRAMSCI, Antonio. Cadernos do cárcere, v.1. Introdução ao estudo da filosofia; A filosofia de Benedetto Croce. 2. ed. Rio de Janeiro: Civilização Brasileira, 2001. 


\section{Trabalhonecessário}

Issn: 1808 - 799X

ano 12, no $18-2014$

GRAMSCI, Antonio. Cadernos do Cárcere, v.2. Os intelectuais; O princípio educativo; Jornalismo. 2.ed. Rio de Janeiro: Civilização Brasileira, 2001. GRAMSCI, Antonio. Cadernos do Cárcere, v.5. I/ Risorgimento - notas sobre a história da Itália. 2.ed. Rio de Janeiro: Civilização Brasileira, 2002.

GRAMSCI, Antonio. Concepção dialética da história. 3.ed. Rio de Janeiro: Civilização Brasileira, 1978.

HARVEY, David. Condição pós-moderna. 14. ed. São Paulo: Edições Loyola, 2005.

HOBSBAWM, Eric. Era dos extremos: o breve século XX: 1914 - 1991. 2. ed. São Paulo: Companhia das Letras, 2005.

MATTOS, Marcelo Badaró. E.P. Thompson e a tradição e crítica ativa do materialismo histórico. Rio de Janeiro: Editora UFRJ, 2012.

MARX, Karl.O capital: crítica da economia política: livro I, v. I. 22. ed. Rio de Janeiro: Civilização Brasileira, 2004.

MARX Karl. Teses sobre Feuerbach In: MARX, Karl; ENGELS, Friedrich. $A$ ideologia alemã. 3ª reimpr. 2. Ed. São Paulo; Martins Fontes, 2002.

MULHERN, Francis. A política dos estudos culturais. In: WOOD, Ellen; FOSTER, John Bellamy (Orgs.). Em defesa da História. Rio de Janeiro: Jorge Zahar, 1999. RUMMERT, Sonia; VENTURA, Jaqueline. Dossiê: Educação de Jovens e Adultos: novos diálogos frente às dimensões contextuais contemporâneas. Educar em Revista[online]. 2007, n.29. Disponível em http://www.scielo.br/scielo.php?pid=S0104-0602007000100004\&script=sci_arttext SANTOS, Boavetura de Souza. Da ciência moderna ao novo senso comum. Porto, Pt.: Edições Afrontamento, 2000.

SANTOS, Boavetura de Souza. Um discurso sobre as ciências. 13. ed. Porto, Pt.: Edições Afrontamento, 2002.

SAVIANI, Demerval. A nova lei da educação: trajetória, limites e perspectivas. 8. ed. Campinas, SP: Autores Associados, 2003. 


\section{Trabalhonecessário}

Issn: 1808 - 799X

ano 12, no $18-2014$

SCHAFF, Adam. História e verdade. 3. ed. Lisboa: Editorial Estampa, 2000. SILVEIRA, Zuleide. Contradições entre capital e trabalho: concepções de educação tecnológica na reforma do ensino médio e técnico. Jundiaí: Paco Editorial, 2010.

SILVEIRA, Zuleide. Organismos supranacionais: a construção de uma concepção de mundo em torno da integração da educação superior - o caso do Brasil.

Revista Trabalho Necessário [on line].UFF:NEDDATE, ano 10, nำ 14, 2012. SPIRO, Melford E. Algumas reflexões sobre o determinismo e o relativismo culturais com especial referência à emoção e à razão. Educação, Sociedade \& Culturas. Porto, Pt.: Universidade do Porto, 1998, pp.197-230. Disponível em: http://www.fpce.up.pt/ciie/revistaesc/ESC9/9-arquivo.pdf.

STÁLIN, Joseph (1938). Sobre o Materialismo Dialético e o Materialismo Histórico, edições Horizonte, Rio, 1945. Transcrição e HTML de Fernando A. S. Araújo. Disponível em http://www.marxists.org/portugues/stalin/1938/09/mat-dia-hist.htm

THOMPSON, Edward. P. A formação da classe operária, v. l: a árvore da Liberdade. 3. Ed. São Paulo: Paz e Terra, 2004.

THOMPSON, Edward. P. A formação da classe operária, v. II: A maldição de Adão e. 4. Ed. São Paulo: Paz e Terra, 2002.

THOMPSON, Edward. P. A formação da classe operária, v. III: A força dos trabalhadores. 3. Ed. São Paulo: Paz e Terra, 2002.

THOMPSON, Edward. P. A miséria da teoria/ou um planetário de erros. Tradução: Waltensir Dutra. Copyleft, 2009.

THOMPSON, Edward. P. As peculiaridades dos ingleses e outros artigos. 2. reimp. Campinas, S.P.: EdUnicamp, 2007.

VALENCIA, Adrián Sotelo. Teoria da dependência e desenvolvimento do capitalismo na América Latina. Londrina, PR: Práxis, 2008, p. 109-10.

WILLIAMS, Raymond. Cultura. 3. ed. Rio de Janeiro: Paz e Terra, 2008. 


\section{Trabalhonecessário}

Issn: 1808 - 799X

ano 12, no $18-2014$

Wood, Ellen Meiksins: A chronology of the new left and its successors, or: Who's old-fashioned now?. In: Socialist Register, v. 31: Socialist Register 1995: Why not capitalism?

Disponível

em:

http://socialistregister.com/index.php/srv/article/view/5649.

WOOD, Ellen. O que é a agenda "p s-moderna"?. In: WOOD, Ellen; FOSTER, John Bellamy (Orgs.). Em defesa da História. Rio de Janeiro: Jorge Zahar, 1999.

Recebido em maio de 2014.

Aprovado em junho de 2014. 